\title{
Detecting Intestinal Parasitic Infections in Laboratory Mice
}

\author{
Firas M. B. Alkhashab ${ }^{* 1}$, Aseel Isam Jamal aldeen Alnuri ${ }^{2}$, and Rana Suhail Abdallah Al_Juwari ${ }^{3}$ \\ Department of Biology, Colleague of Education for Girls, University of Mosul, Iraq \\ *Corresponding author's Email: firasalkhashab@uomosul.edu.iq; (D) ORCiD: 0000-0001-9997-6377
}

\begin{abstract}
A total of 150 Laboratory mice divided into four age groups consisted of 4, 6, 8 and 10 weeks old were used in this study by placing each animal individually in a special cage within the period between October 2019 to the end of February 2020 at the Research and Graduate Studies Laboratory University of Mosul, Iraq. This study aimed to investigate intestinal parasitic infections in laboratory mice, stool samples were collected for 150 laboratory mice and periodically to perform laboratory tests that included direct slide examination and using the concentration method to detect eggs of worms and cysts of protozoa parasites, the culture of parasites also was used by prepared manufactured culture media to develop parasites. The infection was diagnosed in $136(90.66 \%)$ mice while the rest $14(9.33 \%)$ mice did not record any parasitic infection (clean). The higher rate of infection $58 \%$ was reported for Trichomonas muris followed by Entamoeba muris and Giardia muris which found in 22\%, 15.3\% respectively. In the other hand the infection with Hymenolepis diminuta was recorded in $16 \%$ from infected cases by identifying the eggs of this worm in stool samples. This study shows the high rate of parasites infection in laboratory mice which might have negative effects on the result of previous scientific researches, in addition to wasting effort, time, and materials.
\end{abstract}

Keywords: Entamoeba muris, Giardia muris, Laboratory mice, Trichomonas muris

\section{INTRODUCTION}

Laboratory animals throughout the previous years contributed significantly to the progress of scientific research at the level of composition and vital function (Clark et al., 1997) and it play`s an essential role in medical experiments, it has been widely used in assessing the safety of many medicines, food and chemicals, In addition to laboratory experiments to diagnose the pathogens of many diseases and to produce vaccines (Tsegaye and Shiferaw, 1999; Velev et al., 2018), however, in some cases, laboratory animals themselves may develop various laboratory causes, especially parasitic agents, which overlap and affect negatively the result of scientific research to be conducted in addition to wasting effort Scientific, time, and material losses (Baker, 2007; Tanideh et al., 2010), These severe parasitic infections may be internal or external and the parasite is one of the organisms that live on or in other types of organisms and that often causes harmful diseases if they are not beneficial to the host and the parasites live parallel to the livelihood these parasites organisms always try to identify and reduce the host's immunity for the purpose of preserving themselves and surviving (Behenke et al., 2003; Evgenya and Oleg, 2020)

The influence of the parasites may extend to the host's behavior (McNair and Timmons, 1977; Webster, 1994) and even alter its immune status (Bashir et al., 2002; Kamal et al., 2002) and its growth (Mullink, 1970) although mice are tolerant to tolerance and reception (Rahemo et al., 2012) large numbers of parasites have reported cases of parasitic infections in them that have reached out of control limits, as in the case of a pinworm, especially if they hit laboratory mice and the arthropod may play an important role in this process by being an intermediate host or a mechanical carrier of these parasites or their larval roles, therefore, the process of diagnosing infection in laboratory mice is a major challenge (Behnke et al., 2003; Baker, 2007; Parkinson et al., 2011) and the parasite's influence may extend to the host's behavior (McNair and Timmons, 1977; Webster, 1994)

The parasites or their eggs confuse the laboratory diagnosis process, which made relying on one laboratory diagnostic method that can give wrong results that negatively affect the overall laboratory work and therefore it is better to use more than one method because the diagnostic process is not easy It is very important to keep in mind that in many cases of parasitic infections like Entamoeba histolyitca were most probably confused with Entamoeba dispar because they did not differentiate morphologically between identical species in microscopic examinations (Mehmet and William, 2003).

The ability of the immune system of wild mice to tolerate and resist parasitic infections is much more than the ability of the immune system of laboratory mice when placed under the same controlled laboratory conditions (Stephen et al., 2017). Therefore, there is a great diversity in the types of parasites that can infect laboratory mice compared to the 
wild (Baker, 2007). So, through the current research, the focus was on most of the intestinal parasitic species that can cause infections in laboratory mice through laboratory tests, since most studies and researchers rely on observing the general morphological health status of laboratory mice when conducting experiments without attention to the microbiological state of the Laboratory mice, which will adversely affect the overall results of scientific research under study.

\section{MATERIALS AND METHODS}

\section{Study samples}

The present study was conducted within the period between October 2019 to the end of March 2020 at the Research and Graduate Studies Laboratory of the Department of Life Sciences, College of Education for Girls, University of Mosul, Iraq to investigate intestinal parasitic infections in laboratory mice of the Swiss type (Swiss albino Balb / C). The study sample included a laboratory examination of 150 laboratory mice (4-10 months of age) that kept in isolated cages in room temperature and fed on the commercial diet (Erbil feed Co., Iraq) and sterile water was prepared for drinking. The all mice were divided into four age groups considered of $4^{\text {th }}, 6^{\text {th }}, 8^{\text {th }}$ and $10^{\text {th }}$ weeks by placing each animal individually in a separate cage within the period between the October 2019 to the end of March 2020.

\section{Sample collection and examination}

Freshly excreted stool samples were collected for 150 laboratory mice and periodically to perform laboratory tests that included direct examination by preparing smear stools stained with iodine and giemsa stain and using the concentration method (highly saturated sodium salt solution) by mixing one gram of freshly excreted stool with $100 \mathrm{ml}$ of distilled water and the sample was filtered through sterile medical gauze and by three layers to remove suspended matter, eject the suspension by centrifuging at speed of $2300 \mathrm{rpm}$ for one minute.

The filtrate was poured and the centrifugation process was repeated at the same speed after adding 2 ml of water. this process was repeated until clear leachate is reached, then add $2 \mathrm{ml}$ of zinc sulfate to the end of the test tube after disposal of the filtrate with the glass slide cover fixed to the test tube and place the sample In a centrifuge at the same speed and time as before, the cover of the slide was raised and fixed to a glass slide and the sample was stained with an iodine dye to detect eggs of worms and cysts of protozoa parasites. A dissection of infected mice was also performed to obtain whole intestinal contents where the animal was anaesthetized with chloroform by placing the lab mouse in a sealed glass chamber containing a piece of cotton wet with the drug (Padmanabhan et al., 1981; Cicero et al., 2018) and the intestine removed and then emptying its contents in a sterile Petri dish with normal saline solution and then prepare the stained slides that examined later by using microscopy (Nicon Co., Japan) at the power of 40X and 100X to diagnose parasitic pathogens, according to method of Parkinson et al. (2011).

\section{The cultivation of parasites}

The process of growing parasites in the laboratory and using prepared and manufactured culture media is one of the important research methods in the process of diagnosing parasites. Therefore, through current research, culture media was used to develop parasites.

\section{Diamond's Medium Trypton, Yeast, Maltose}

This medium, suggested by Shaio et al. (1981) was used to grow the Trichomonas parasite, which is prepared for every $100 \mathrm{ml}$ of distilled water and the following substances: The materials were dissolved in distilled water and mixed using an electric magnetic stirrer for one hour and then filtered using Whatman NO.2 filter paper to get rid of insoluble materials (Table 1). The acid function was set at 6.2 and the sterility of the medium using the sterilizer at $121 \mathrm{C}$ at a pressure of 15 Ibs for 15 minutes (Sobel et al., 1999).

\section{The culture media of the Entamoeba parasite}

Culture media manufactured and imported from the Indian company (HIMEDIA Laboratories) According to the first two mediums, it consists of the following components as mentioned in table 2. The second culture medium, HiVeg Media, which is also imported from the Indian company HIMEDIA Laboratories, consists of the following materials as mentioned in table 3 .

These media were prepared in vivo by dissolving 33 grm of medium powder in $1000 \mathrm{ml}$ of distilled water and mixed using the device of the magnetic electric stirrer and after the powder was completely thawed it was distributed on 
test tubes with a tight cover and the sterility of the medium using the sterilizer at $121 \mathrm{C}$ and pressing $15 \mathrm{Ibs}$ for 15 minutes, after completing the sterilization.

The tubes were placed diagonally to harden, and about half of the inclined surface was covered with sterile and diluted horse serum in a ratio of 1: 6 with a solution of physiological salt added to the middle (5) carrying a loop of sterile rice flour in the oven for one hour at a degree of $161^{\circ} \mathrm{C}$.

These media were inoculated by adding $0.5 \mathrm{ml}$ of the emulsion containing the parasite to the parasite's tubes and incubated for 24 hours at a temperature of $37^{\circ} \mathrm{C}$. The samples were examined to ensure the growth of the parasite every 24 hours by preparing the stained smears and recording the results (Al-Idrise et al., 2008).

\section{Ethical approval}

The present experimental research was conducted in compliance with the health protection guidelines of experimental animals regulated by the ethical committee in the Department of Biology of Mosul University, Iraq and in according to Helsinki declaration on Ethical Principles.

Table 1. Ingredients for Diamond's medium

\begin{tabular}{lcc}
\hline Ingredients & g/l & Company \\
\hline Tryptone soya broth & 2.0 & Thermo Scientific, USA \\
Yeast extract & 1.0 & Thermo Scientifiic, USA \\
D-Maltose & 0.5 & Sigma-Aldrich, USA \\
L-Ascorbic acid & 0.02 & Sigma-Aldrich, USA \\
Agar & 0.05 & Sigma-Aldrich, USA \\
Inhibited human plasma & $10.0 \mathrm{ml}$ & \\
Stryptomycin sulphate & 1.0 & Sigma-Aldrich, USA \\
Nystatine & $500000 \mathrm{IU}$ & Awamedica Pharmaceutical, Iraq \\
\hline
\end{tabular}

Table 2. Ingredients for culture media

\begin{tabular}{lc}
\hline Ingredients & g/l \\
\hline Liver infusion & 272.0 \\
Protease pepton & 5.5 \\
Sodium Beta - glycerophosphate & 3.0 \\
Sodium chloride & 2.7 \\
Agar & 11.0 \\
\hline
\end{tabular}

Table 3. The culture medium

\begin{tabular}{lc}
\hline Ingredients & g/l \\
\hline HiVeg infusion & 10.0 \\
HiVeg peptone & 5.5 \\
Sodium Beta - glycerophosphate & 3.0 \\
Sodium chloride & 2.7 \\
Agar & 11.0 \\
\hline
\end{tabular}

\section{RESULTS AND DISCUSSION}

The infection was diagnosed in 136 mice $(90.66 \%)$ while the rest 14 mice $(9.34 \%)$ mice did not record any infection. As presented in table 4, the higher rate of infection, 58\% was reported for Trichomonas muris. Figure 1 is exactly in agreement with the finding of Bicalho et al. (2007) and Rahemo et al. (2012). As well as the result was shown that the rate of infection of Entamoeba muris (figure 2) and Giardia muris (figure 3) was 22\%, 15.3\% respectively infection with these parasites was lower than the result that noticed by Rahemo et al. (2012), but it`s disagreement with the result of Bicalho et al. (2007). In other hand, the infection with Hymenolepis diminuta was recorded in $16 \%$ of infected cases by identification of the eggs of this worm (figure 4). The high rate of infection may be due to the living of mice in the same plastic cage, dirty wooden chips and contamination of water and food, but the lower rate, $11.3 \%$ was observed for 
Balantidium coli, (figure 5) it has been considered as the reservoir. When performing a diagnostic laboratory examination of stool samples overlap, leading to a misdiagnosis of the sample due to the presence of parasitic arthropods as shown in (figure 6) (Reedha and Aseel, 2019).

In table 5, the results indicated that the overall rate of infection with different types of intestinal parasites was $90.66 \%$ most of the infections were single parasites $(70.67 \%)$. The results showed there is equals bilateral and multiple infections (10\%). The higher rate of bilateral infection was with Trichomonas muris and Hymenolepis diminuta. In multiple infections the higher rate was for Trichomonas muris, Entamoeba muris, and Hymenolepis diminuta (4.67\%). The Trichomonas muris and Entamoeba muris are classified commensal agents as they are not associated with animal health alterations with probable involvements in experimental outcomes. Sharp and La Regina (1998) declared Giardia muris as a pathogenic agent. These results have converged with the results of Rahemo et al. (2012) which indicated that the highest rate of infection by Trichomonas muris and this study showed infection by Giardia muris. The infection with Hymenolepis diminuta was observed in this study which had reported by Garedaghi and Khaki (2014) that found some rodents with the same infection.

Table 4. Diagnosed parasites in fresh fecal smears of mice

\begin{tabular}{lccc}
\hline Smear No & Parasite & +ve & Percent \\
\hline $1-$ & Entamoeba muris & 33 & 22 \\
$2-$ & Trichomonas muris & 87 & 58 \\
$3-$ & Giardia muris & 23 & 15.3 \\
$4-$ & Balantidium coli & 17 & 11.3 \\
$5-$ & Hymenolepis diminuta & 24 & 16 \\
\hline
\end{tabular}

No: number; $* 150$ mice were studied

Table 5. Type of infections in the stool of examined mice.

\begin{tabular}{|c|c|c|}
\hline Parasites & Number of infections & Percent \\
\hline \multicolumn{3}{|l|}{ Single parasitic infection } \\
\hline Entamoeba muris & 13 & 8.67 \\
\hline Trichomonas muris & 65 & 43.33 \\
\hline Giardia muris & 12 & 8 \\
\hline Balantidium coli & 5 & 3.33 \\
\hline Hymenolepis diminuta & 11 & 7.33 \\
\hline Total & 106 & 70.67 \\
\hline \multicolumn{3}{|l|}{ Co-parasitic infection } \\
\hline Entamoeba muris \& Giardia muris & 3 & 2 \\
\hline Trichomonas muris \& Balantidium coli & 4 & 2.67 \\
\hline Trichomonas muris \& Hymenolepis diminuta & 6 & 4 \\
\hline Trichomonas muris \& Entamoeba muris & 2 & 1.33 \\
\hline Total & 15 & 10 \\
\hline \multicolumn{3}{|l|}{ Multi parasitic infection } \\
\hline Trichomonas muris, Giardia muris, Entamoeba muris \& Balantidium coli & 3 & 2 \\
\hline Trichomonas muris, Entamoeba muris \& Hymenolepis diminuta & 7 & 4.67 \\
\hline Giardia muris, Entamoeba muris \& Balantidium coli & 5 & 3.33 \\
\hline Total & 15 & 10 \\
\hline
\end{tabular}




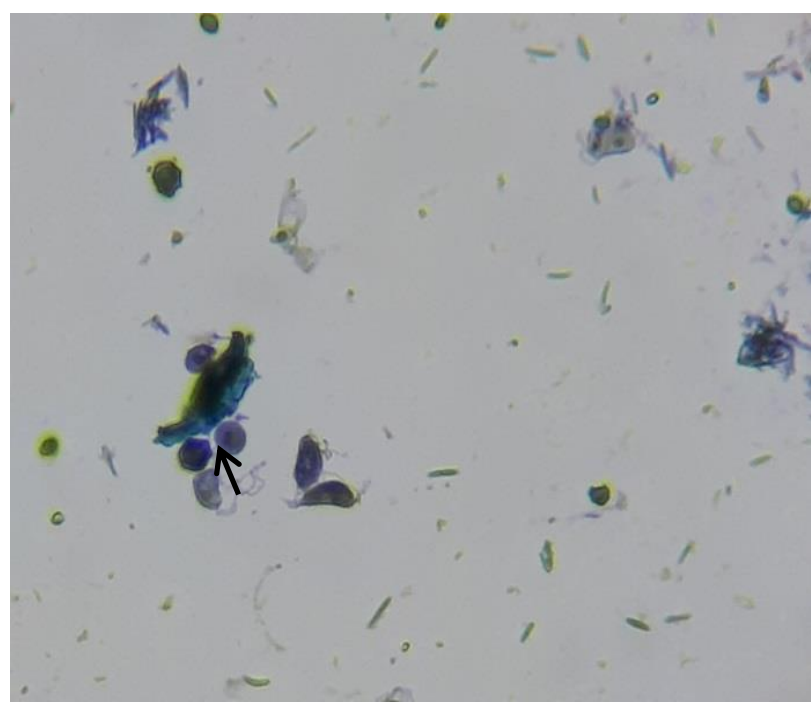

Figure 1. Microscopic view of Trichomonas muris trophozoite (arrow) from mice fecal sample stained by giemsa stain ( $\times 40$ magnification)

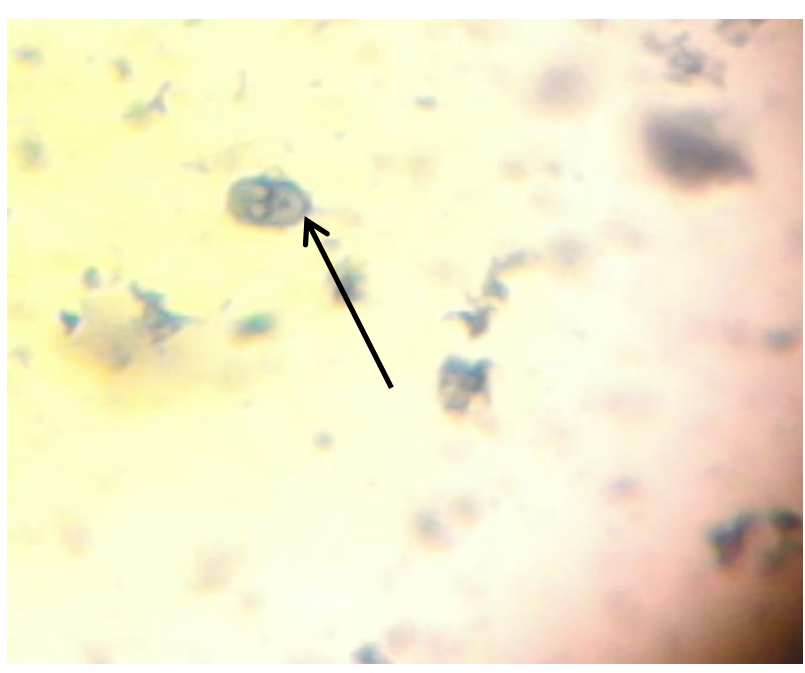

Figure 3. Microscopic view of Giardia muris trophozoite (arrow) from mice fecal sample stained by iodin stain $(x$ 40 magnification)

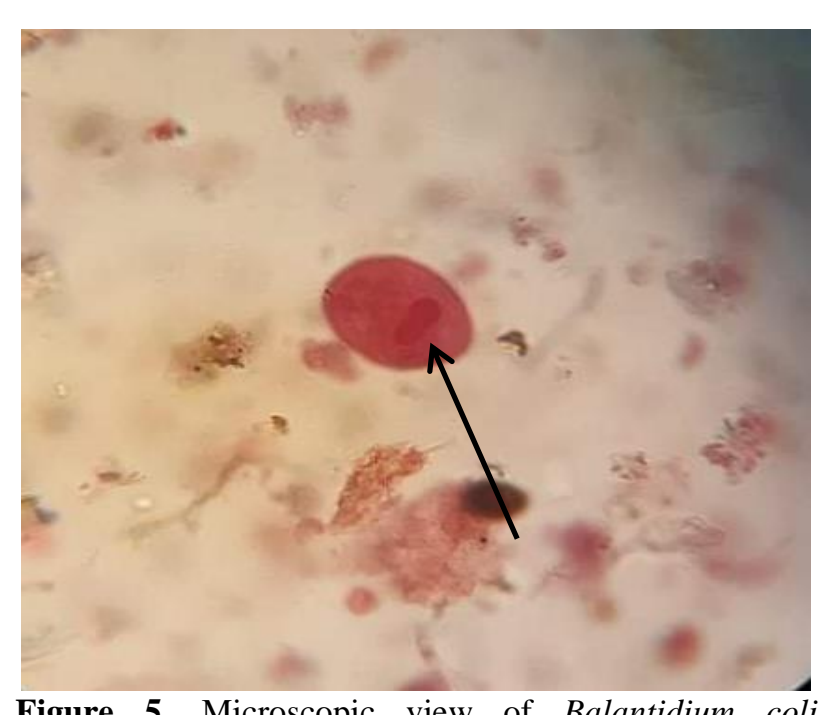

Figure 5. Microscopic view of Balantidium coli trophozoite (arrow) from mice fecal sample stained by giemsa stain ( $\times 40$ magnification)

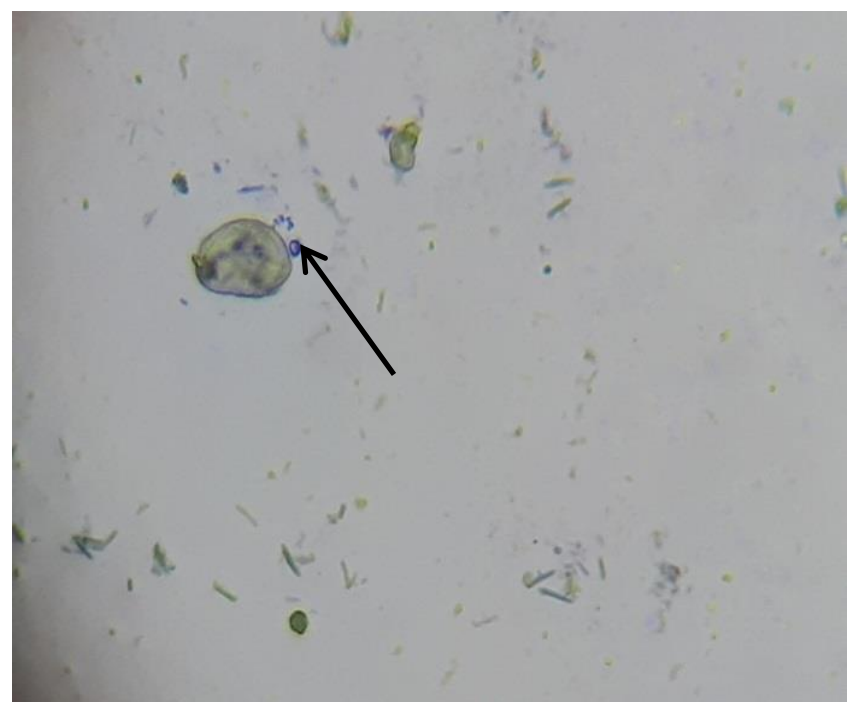

Figure 2. Microscopic view of Entamoeba muris cysts (arrow) from mice fecal sample stained by iodine stain $(\times 40$ magnification)

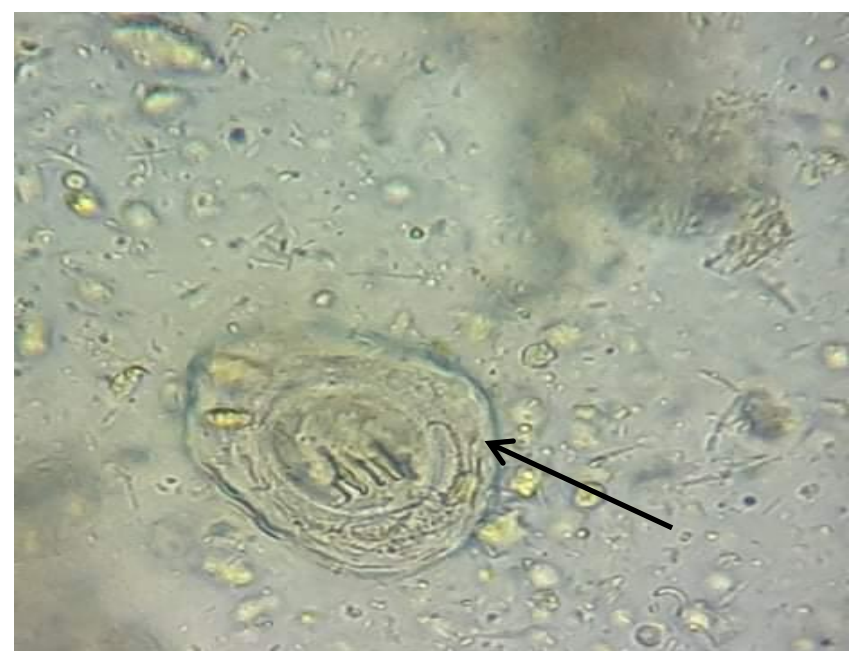

Figure 4. Microscopic view of Hymenolepis diminuta egg (arrow) from mice fecal sample (× 100 magnification)

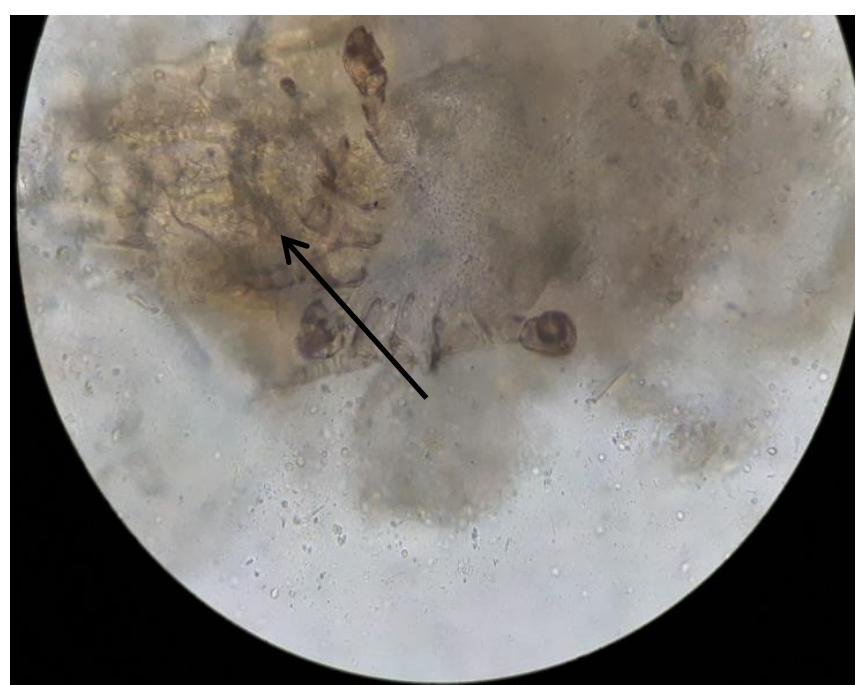

Figure 6. Microscopic view of adult Tick (arrow) from mice fecal sample ( $\times 40$ magnification) 


\section{DECLARATIONS}

\section{Authors' contribution}

Firas M. B. Alkhashab contributed to data analysis and manuscript writing and performed the experimental works Aseel Isam Jamal aldeen Alnuri and Rana Suhail Abdallah Al_Juwari were involved in the development of the methodology and experimental works. Finally, after careful consideration, the final revised manuscript was approved by all authors.

\section{Competing interests}

The authors have declared no conflict of interest.

\section{Acknowledgments}

The authors express their gratitude to the president of Mosul University and the deanship of the Colleague of Education for Girls and the deanship of the Colleague of Veterinary Medicine by providing laboratory materials and equipment and helping to provide laboratory mice and cages which contributed greatly to the completion of this study.

\section{REFERENCES}

Al-Idrrisi SR, AL-Aziz, SAA, AL-Emara GY and AL-Badran ASH (2008). Culture of Entamoeba histolytica in vitro. AL-Qadisiya Journal of Veterinary Medicine Sciences, 7(1): 28-33. Available at: http://qu.edu.iq/vmjou/wp-content/uploads/2015/01/Vol.-71En.-28-33.pdf

Baker DG (2007). Flynn's parasites of Laboratory Animals. 2nd ed. American College of Laboratory Animal Medicine, Blackwell Publishing, USA. Preface, pp. 1-15. available at: https://www.wiley.com/en-us/Flynn\%27s+Parasites+of+Laboratory+Animals\%2C+2nd+Edition-p9780470344170\#content-section

Bashir ME, Andersen P, Fuss IJ, Shi HN and Nagler Anderson C (2002). An enteric helminth infection protects against an allergic response to dietary antigen. The Journal of Immunology, 169: 3284-3292. DOI: 10.4049/jimmunol.169.6.3284

Behnke JM, Iraqi F, Menge D, Baker RL, Gibson J and Wakelin D (2003). Chasing the genes that control resistance to gastrointestinal nematodes. Journal of Helminthology, 77: 99-110. Available at: https://www.ncbi.nlm.nih.gov/pubmed/12756063

Behnke JM, Lowe A, Clifford S and Wakelin D (2003). Cellular and serological responses in resistant and susceptible mice exposed to repeated infection with Heligmosomoides polygyrus bakeri. Parasite Immunology, 25:333-40. DOI:10.1046/j.1365-3024.2003.00639.x

Bicalho KA, Araujo FTM, Rocha RS and Carvalho OS (2007). Sanitary profile in mice and rat colonies in laboratory animal houses in Minas Gerais: Endo and ectoparasites. Arquivo Brasileiro de Medicina Veterinária e Zootecnia, 59(6): 1478-1484. DOI: https://doi.org/10.1590/S0102$\underline{09352007000600020}$

Cicero L, Fazzotta S, Davide Palumbo Vincenzo, Cassata G and Ignazio Lo Monte A (2018). Anesthesia protocols in laboratory animals used for scientific purposes. Acta Biomedicine, 89(3): 337-342. DOI: https://doi.org/10.23750/abm.v89i3.5824

Clark HE, Coats ME, Eva JK, Ford DJ, Miliner CK, O, Dorogue PN, Scott PP and Ward RJ (1997). Dietary standards for laboratory animals: Report of laboratory animals Center Diets Advisory Committee. Laboratory Animals Report, 11:1-4. DOI: https://doi.org/10.1258/002367777780959175

Garedaghi Y and Khaki AA (2014). Prevalence of Gastrointestinal and Blood Parasites of Rodents in Tabriz, Iran, with Emphasis on Parasitic Zoonoses. Crescent Journal of Medical and Biological Science, 1 (1): 2148: 9696. Available at: http://www.cjmb.org/pdf.php?id=128

Kamal M, Dehlawi MS, Brunet LR and Wakelin D (2002). Paneth and intermediate cell hyperplasia induced in mice by helminth infection. Parasitology, 125: 275-81. DOI: https://doi.org/10.1017/S0031182002002068

McNair DM and Timmons EH (1977). Effect of Aspiculuris tetraptera and Syphacia obvelata on exploratory behavior of an inbred mouse strain. Laboratory Animal Science, 27: 38-42. Available at: https://link.springer.com/article/10.2478/s11687-006-0038-5

Mullink JW (1970). Pathological effects of oxyuriasis in the laboratory mouse. Laboratory Animal 4: 197-201. DOI: https://doi.org/10.1590/s198429612019072

Padmanabhan R, Singh G and Singh S (1981). Malformations of the Eye Resulting from Maternal Hypervitaminosis a During Gestation in the Rat. Acta Anatomica, 110(4):291-298. DOI: https://doi.org/ 10.1159/000145439

Parkinson CM, O Brien A, Albers TM, Simon MA, Clifford CB and Pritchett Corning KR (2011). Diagnosis of ecto and endoparasites in laboratory rats and mice. Journal of Visualized Experiments, p. e2767. DOI: https://doi.org/10.3791/2767

Rahemo ZIF, Rezan K and Qaraman MK (2012). Intestinal Parasites of Experimental Rodents with Testing the Efficacy of Diagnostic Methods. International Journal of Pharmaceutical Research, 2: 77-81.

Reedha N and Aseel I (2019). Isolation and identification of parasites from housefly (musca domestica) in Mosul City, Iraq. Advances in Animal and Veterinary Sciences, 7(8): 711-714. DOI: https://doi.org/10.17582/journal.aavs/2019/7.8.711.71

Shaio MF, Lo HS and Huang SW (1981). Trichomonas hominis: isolation and axenic cultivation. Chinese Journal of Microbiology, 14: 73-77. PMID: 7030663

Sharp PE and La Regina MC (1998). Nutrition and Biochemistry. In: Suckow MA, Weisbroth SH, Franklin CF, eds. The Laboratory Rat. 2nd ed. London, CRC Press.

Sidor EA and Andreyanov ON (2020). The role of glycogen in biological cycle of Trichinella spiralis. World's Veterinary Journal, 10(4): 30-34. DOI: https://dx.doi.org/10.36380/scil.2020.wvj4

Stephen A, Elizabeth C, Luke L, Laura W, Louise H, Drescher P, Raynes JG, Julius CR, Hafalla ME, Eleanor V and Riley M (2017). The comparative immunology of wild and laboratory mice, Mus musculus domesticus. Nature Communications, 8: 14811. DOI: https://doi.org/10.1038/ncomms14811

Tanideh N, Sadjjadi SM, Mohammadzadeh T and Mehrabani D (2010). Helminthic Infections of Laboratory Animals in Animal House of Shiraz University of Medical Sciences and the Potential Risks of Zoonotic Infections for Researchers. Transgenic. Iranian Red Crescent Medical Journal, 12(2): 151-157. Available at: https://www.academia.edu/5163301/

Tsegaye K and Shiferaw A (1999). Factors Affecting Quality of Laboratory Services in Public and Private Health Facilities in Addis Ababa, Ethiopia. Ethiopian Health and Nutrition Research Institute, Department of Laboratory services. Ethiopian Journal of Health Development, 13 (1): $49-45$. Available at: https://pubmed.ncbi.nlm.nih.gov/29075171/ 
Velev V, Iankov I, Haralambieva I, Pavlova M, Mangarov I and Mitov I (2018). Production of Monoclonal Antibodies against Common Epitopes of Salmonella by Oral Immunization of Laboratory Animals. Global Journal of Research and Review, 5:1. Available at: http://www.imedpub.com/articles/production-of-monoclonal-antibodies-against-common-epitopes-of-salmonella-by-oral-immunization-oflaboratory-animals.php?aid=21872

Webster JP (1994). The effect of Toxoplasma gondii and other parasites on activity levels in wild and hybrid Rattus norvegicus. Parasitology, 109: 583-589. DOI: https://doi.org/10.1017/S0031182000076460 